\section{Core-shell in liquid chromatography: application for determining sulphonamides in feed and meat using conventional chromatographic systems}

\author{
Antonio Armentano, ${ }^{1}$ Simona Summa, \\ Sonia Lo Magro, ${ }^{1}$ Pasquale D'Antini, \\ Carmen Palermo, ${ }^{2}$ Marilena Muscarella ${ }^{1}$ \\ 'Pharmacology and Toxicology Unit, \\ Complex Structure of Chemistry, Institute \\ for Experimental Veterinary Medicine of \\ Apulia and Basilicata, Foggia; \\ 2Department of Agricultural, Food, and \\ Environmental Sciences, University of \\ Foggia, Foggia, Italy
}

\section{Abstract}

A C18 column packed with core-shell particles was used for the chromatographic separation of sulphonamides in feed and meat by a conventional high performance liquid chromatography system coupled with a diode array detector. Two analytical methods, already used in our laboratory, have been modified without any changes in the extraction and clean-up steps and in the liquid chromatography instrumentation. Chromatographic conditions applied on a traditional 5 - $\mu \mathrm{m}$ column have been optimized on a column packed with 2.6 $\mu \mathrm{m}$ core-shell particles. A binary mobile phase [acetate buffer solution at $\mathrm{pH} 4.50$ and a mixture of methanol acetonitrile 50: $50(\mathrm{v} / \mathrm{v})]$ was employed in gradient mode at the flow rate of $1.2 \mathrm{~mL}$ with an injection volume of $6 \mu \mathrm{L}$. These chromatographic conditions allow the separation of 13 sulphonamides with an entire run of 13 minutes. Preliminary studies have been carried out comparing blanks and spiked samples of feed and meat. A good resolution and the absence of interferences were achieved in chromatograms for both matrices. Since no change was made to the sample preparation, the optimized method does not require a complete revalidation and can be used to make routine analysis faster.

\section{Introduction}

Sulphonamides (SAs) are derivatives of paminobenzenesulfonic acid and represent one of the most common and oldest class of antimicrobial drugs. SAs act as bacteriostatic agents and possess chemotherapeutic activity against infection caused by gram-positive and gramnegative bacteria and some protozoa. The high efficiency and their low cost are the main cause of their large use in veterinary practices. SAs are used in veterinary medicine also in combination with other antibiotics not only to combat infectious diseases, but also as additives to animal feed in order to promote growth and to increase the productivity. However for this purpose, the use of these substances is illegal in different nations (Dmitrienko et al., 2014).

Different medicated/supplemented feeds are usually produced one after the other in the same manufacturing line. Consequently, traces of active ingredients may remain in the production line and mix with the batches of the next product (Segato et al., 2011). Crosscontamination occurs when traces of drugs or chemicals remain into feeds that should not contain any therapeutic substance (Borras et al., 2011). This carry-over seems that can occur during transport to farms or even at the farm (Kan and Meijer, 2007; Segato et al., 2011). The SAs intake by the animals through the feed causes their distribution and presence in all tissues.

SAs presence in non-target feed and in food of animal origin is of great concern and represents a risk for the health of animal species and consumers. The systematic human exposure to SAs through their residues in food may cause allergic reactions, suppression of enzyme activity, alteration of the intestinal microflora and promotion of pathogen forms. Additionally, some SAs can be responsible of hemotoxicity and carcinogenic effects. The presence of SAs has to be consequently monitored in feed and in food of animal origin to guarantee food safety to the consumers. The Italian authorities have included in the National Regulatory Monitoring Plan of drug residues and contaminants in products of animal origin (Piano Nazionale Residui - PNR) and in feedingstuffs (Piano Nazionale Alimentazione Animale - PNAA), the control of SAs in different matrices such as feed and meat. Methods based on enzyme linked immunosorbent assay (ELISA) are suitable for screening purpose. However, both liquid chromatography coupled to tandem mass spectrometry (LC-MS/MS) and high performances liquid chromatography with diode array detection (HPLC/DAD) can be used for confirmatory methods in feed and meat samples. Chromatographic separations of drugs residues in few minutes with high efficiency and resolution are a challenge for an official control laboratory with high samples throughput. Additionally, short analysis times require a less quantity of mobile phase, with the advantage of reducing solvents consumption and their discharge as waste. Using traditional 5
Correspondence: Marilena Muscarella, Pharmacology and Toxicology Unit, Complex Structure of Chemistry, Institute for Experimental Veterinary Medicine of Apulia and Basilicata, via Manfredonia 20, 71121 Foggia, Italy.

Tel. +39.0881 .786353 - Fax: +39.0881 .786362 .

E-mail: marilena.muscarella@izspb.it

Key words: Core-shell; Sulphonamides; Liquid chromatography.

Conflict of interest: the authors declare no potential conflict of interest.

Received for publication: 15 July 2016. Accepted for publication: 22 September 12016.

This work is licensed under a Creative Commons Attribution-NonCommercial 4.0 International License (CC BY-NC 4.0).

(C) Copyright A. Armentano et al., 2016

Licensee PAGEPress, Italy

Italian Journal of Food Safety 2016; 5:6166

doi:10.4081/ijfs.2016.6166

$\mu \mathrm{m}$ totally porous particle columns, a chromatographic separation of a large number of analytes (10-15 molecules) is obtained in no less than 30 minutes, including the step of column washing. Fast chromatographic runs can be easily achieved by using sub- $2 \mu \mathrm{m}$ totally porous particle columns. However, these columns require ultra performance liquid chromatography (UPLC) (Gritti and Guiochon, 2012) able to work at pressure around 1000 bar. In the new chromatographic column scenario, analytical columns packed with coreshell particles offer short chromatographic separation time and efficiency comparable to sub-2 $\mu \mathrm{m}$ totally porous particles with the advantage of a low back pressure ( $\leq 400$ bar) (Fekete et al., 2012; Guiochon and Gritti, 2011; Hayes et al., 2014). This allows the use of these columns on conventional HPLC system without any up-grade on the instrumentation. In our laboratory two validated analytical methods based on the use of HPLC/DAD are already employed to cover the requests of official control analysis of $10 \mathrm{SAs}$ in feed (Iammarino et al., 2011) and 13 in meat (Lo Magro et al., 2012). Both methods use traditional chromatographic column packed with $5 \mu \mathrm{m}$ particles and allow the chromatographic separations of the SAS in 40-45 minutes. In this work, it is described how these methods have been modified employing a new stationary phase, in order to significantly reduce the chromatographic running time and improving the chromatographic efficiency. This was achieved without any variation in the preparation and clean-up steps. 


\section{Materials and Methods}

\section{Chemicals}

Ammonia solution (30\%), acetic acid (99.5\%), n-hexane (95\%), ammonium acetate ( $\geq 98 \%$ ), were purchased from Carlo Erba Reagents (Rodano, Italy). Chloroform and acetone (analytical grade) were obtained from Panreac (Barcelona, Spain). Water, acetonitrile and methanol of HPLC grade were purchased from Baker (Deventer, Holland). The $0.02 \mathrm{M}$ acetate buffer solution, used as solution (A) for HPLC mobile phase, was prepared by dissolving $1.54 \mathrm{~g}$ of ammonium acetate in water. The $\mathrm{pH}$ value was adjusted to $4.50 \pm 0.02$ with acetic acid. Standards of SAs [sulfadiazine (SDA) 99.3\%, sulfathiazole (STZ) 99.9\%, sulfapyridine (SP) $99.7 \%$, sulfamerazine (SM) 98.8\%, sulfamethazine (SMZ) 99.8\%, sulfamethoxipyridazine (SMP) 99.7\%, sulfachloropyridazine (SCP) 99.4\%, sulfamonomethoxine (SMM) 98\%, sulfamethoxazole (SMX) 99.9\%, sulfadoxine (SD0) 99.8\%, sulfaphenazole (SNZ) 99\%, sulfadimethoxine (SDM) $99.8 \%$ and sulfaquinoxaline (SQX) $96 \%$ ] were supplied by Sigma-Aldrich (Steinheim, Germany).

Working standards at concentration of 0.25 0.5-1.0-2.0-4.0 mg/L were prepared by appropriate dilution in mobile phase to make calibrations curves for the detection of SAs in meat. A feed sample fortified at five concentrations $(0.2,1.0,5.0,10.0$ and $20.0 \mathrm{mg} / \mathrm{kg})$ with standard solutions of SAs before the extraction was used to obtain the calibration curve for the analysis of SAs in feed.

\section{Apparatus and chromatographic conditions}

Chromatographic separations were performed on an HPLC system, Agilent Technologies SL 1200 Series (Waldbronn, Germany) equipped with diode array detector. The optimized conditions for the separations of SAs were obtained using Phenomenex (Torrance, CA, USA) Kinetex core-shell C18 column $(75 \mathrm{x} 4.6 \mathrm{~mm}$ i.d., particle size $2.6 \mu \mathrm{m})$ at a flow rate of $1.2 \mathrm{~mL} / \mathrm{min}$ adopting the elution gradient reported in Table 1 . The initial composition of mobile phase was $0.02 \mathrm{M}$ acetate buffer solution at $\mathrm{pH} 4.50 \pm 0.02(\mathrm{~A})$ and a mixture of methanol/acetonitrile $50: 50(\mathrm{v} / \mathrm{v})$ (B) in a ratio of 90:10 (v/v). The injection volume was $6 \mu \mathrm{L}$ and the column temperature was set at $40^{\circ} \mathrm{C}$. The chromatographic conditions have been obtained with the support of a software available on-line HPLC method development calculator (www.hplctransfer.com). The data acquisition was carried out in the range of wavelengths between 220 and $360 \mathrm{~nm}$ with $270 \mathrm{~nm}$ as main wavelength of detection, 600 $\mathrm{nm}$ as reference wavelength and a bandwidth of $4 \mathrm{~nm}$.

\section{Sample collection}

The feed (for poultry) and meat (beef) samples used for the method optimization were collected by farms of Apulia and Basilicata. The feed samples, before analysis, were stored at room temperature in a cool and dry place and finely grounded by a commercial mill. The meat samples were stored at $-20^{\circ} \mathrm{C}$ and homogenized by a mixer before analysis.

\section{Sample preparation}

The preparation and sample clean-up procedure for both matrices are already reported (Lo Magro et al., 2012; Iammarino et al., 2011).

\section{Meat}

A 15-g portion of homogenate sample was treated with $3 \mathrm{~mL}$ of $10 \%$ acetic acid solution. A volume of $25 \mathrm{~mL}$ of a chloroform/acetone mixture (50/50, v/v) was added and the solution agitated using an ultrasonic bath for 20 min. This extraction step was repeated. The two extracts were combined in a polypropylene tube and centrifuged at $2209 \mathrm{~g}$ for $10 \mathrm{~min}$ at $20^{\circ} \mathrm{C}$ and left at $-70^{\circ} \mathrm{C}$ for $30 \mathrm{~min}$, to better separate the organic phase from supernatant aqueous layer. A volume of $4 \mathrm{~mL}$ of glacial acetic acid was added to a $40 \mathrm{~mL}$ of organic phase, before the clean-up step, by an SPE benzensulphonic SCX cartridge (Phenomenex). The cartridge was conditioned with $6 \mathrm{~mL}$ of $\mathrm{n}$ hexane and $6 \mathrm{~mL}$ of a $5 \%$ acetic acid in chloroform/acetone. After the solution sample loading, the column was washed with $5 \mathrm{~mL}$ of water and $5 \mathrm{~mL}$ of methanol. The fraction containing the SAs was eluted with $13 \mathrm{~mL}$ of a $2.5 \%$ methanol/ammonia solution. The eluate was evaporated to dryness at $45^{\circ} \mathrm{C}$ and the residue was reconstituted in $0.5 \mathrm{~mL}$ of mobile phase, filtered and injected in HPLC.

\section{Feed}

A $2 \mathrm{~g}$ of sample was treated with $20 \mathrm{~mL}$ of chloroform/acetone mixture $(50 / 50, \mathrm{v} / \mathrm{v})$ and vortex for few minutes. After centrifugation and filtration on paper, $1 \mathrm{~mL}$ of acetic acid was added to $9 \mathrm{~mL}$ of extract. A volume of $10 \mathrm{~mL}$ of solution was used for the clean-up step by SPE benzensulphonic SCX cartridge (Phenomenex) conditioned with $6 \mathrm{~mL}$ of $5 \%$ acetic acid solution. After washing with $3 \mathrm{~mL}$ of water and $3 \mathrm{~mL}$ of methanol, SAs were eluted with $10 \mathrm{~mL} 2.5 \%$ ammoniacal methanol solution. The eluate was evaporated to dryness at $45^{\circ} \mathrm{C}$ and the residue was reconstituted in 5 $\mathrm{mL}$ of mobile phase, filtered and injected.

\section{Results}

The HPLC/DAD method (Iammarino et al., 2011), already used in our laboratory for the determination of 10 sulphonamides (SDA, STZ, SM, SMZ, SMP, SCP, SMM, SDM, SQX) in feed, is based on the use of a traditional $\mathrm{C} 18$ chromatographic column [C18 LUNA column (250x4.6 mm i.d., particle size $5 \mu \mathrm{m}$ )] set at $30^{\circ} \mathrm{C}$. An elution gradient (Table 1) was applied with a flow rate of $1 \mathrm{~mL} / \mathrm{min}$, and an injection volume of $20 \mu \mathrm{L}$ was used. The method was submitted to a complete in-house validation following the guidelines described in the Decision 657/2002/EC (European Comission, 2002) taking into account the most important parameters reported in the Regulation 882/2004/EC (European Comission, 2004). The chromatograms of a blank (A) and a spiked feed sample at $10 \mathrm{mg} / \mathrm{kg}$ of SAs (B) obtained with this method are reported in Figure 1. For the complete separation of the ten SAs and for the column re-equilibration $\mathbf{4 5}$ minutes are required.

The HPLC/DAD method used in our laboratory to analyze 13 sulphonamides (SDA, STZ, SP, SM, SMZ, SMP, SCP, SMM, SMX, SDO, SNZ. SDM and SQX) in meat (Lo Magro et al., 2012) employs the same chromatographic conditions reported for feed with the exception of the column temperature $\left(40^{\circ} \mathrm{C}\right)$ and elution gradient

Table 1. Elution gradients used for the acquisition of the chromatograms reported in Figures 1 and 2. Mobile phase A: $0.02 \mathrm{M}$ acetate buffer solution at $\mathrm{pH}$ 4.50; mobile phase B: methanol/acetonitrile 50:50 (v/v). C18 LUNA column $(250 \times 4.6 \mathrm{~mm}$ i.d., particle size $5 \mathrm{um}$ ) was used with gradients $\mathrm{a}$ and b; kinetex core-shell $\mathrm{C} 18$ column $(75 \times 4.6 \mathrm{~mm}$ i.d., particle size $2.6 \mu \mathrm{m}$ ) was used with gradient c.

\begin{tabular}{llcccccc} 
Gradient & & & & & & \\
a & Time (min) & 0 & 30 & 35 & 45 & & \\
& A (\%) & 85 & 59 & 85 & 85 & & \\
& B (\%) & 15 & 41 & 15 & 15 & & \\
b & Time (min) & 0 & 15 & 20 & 35 & 37 & 40 \\
& A (\%) & 85 & 71 & 67 & 40 & 85 & 85 \\
& B (\%) & 15 & 29 & 33 & 60 & 15 & 15 \\
\hline c & Time (min) & 0 & 6 & 7 & 9.20 & 12 & 13 \\
& A (\%) & 90 & 71 & 67 & 35 & 90 & 90 \\
& B (\%) & 10 & 29 & 33 & 65 & 10 & 10 \\
\hline
\end{tabular}


(Table 1). The chromatogram of a blank (C) and spiked meat sample at $100 \mu \mathrm{g} / \mathrm{kg}$ of SAs (D) are reported in Figure 1. The required time for the separation of $13 \mathrm{SAs}$ is around 30 minutes with a further time of 10 min for the washing column step.

In order to reduce the chromatographic separation time and consequently to save solvent, the existing analytical methods have been adapted on the new core- shell column. The preparation sample in both cases (feed and meat) was not modified. The elution gradient and the flow rate suggested by the software were optimized in order to improve the peak separations and to avoid the co-elution among the analyte peaks and matrix interferences. The best conditions, for both matrices, have been obtained using an injection volume of 6 $\mu \mathrm{L}$ and applying the gradient reported in Table 1 , with a flow rate of $1.2 \mathrm{~mL} / \mathrm{min}$. A comparison between the chromatograms of blank samples (A for feed and $\mathrm{C}$ for meat) is reported in Figure 2. The chromatographic results obtained for the spiked samples using the new column are also shown in Figure 2 where the chromatograms of a spiked feed sample at 10 $\mathrm{mg} / \mathrm{kg}$ of SAs (B) and of spiked meat sample at the SAs concentration of $100 \mu \mathrm{g} / \mathrm{kg}$ (D) are reported.

\section{Discussion}

The 5- $\mu \mathrm{m}$ traditional chromatographic column (Figure 1) allows the separation of 10 SAs in feed and 13 in meat with a good resolution with an acceptable baseline profile. Although the interferences due to the matrix effect do not represent an issue, the entire chromatographic run requires 40-45 minutes.

The use of the new core-shell columns permits the separation of the same molecules in only 13 minutes (Figure 2). This significant reduction of the analysis time gives the possibility to analyze a large number of samples in a reasonable time. Consequently, there is a less consume of mobile phase, which represent not only an economic advantage, but also an environment friendly aspect.

From the chromatographic point of view, the improvement of the narrow profile of the chromatographic peaks obtained by using the core shell column is highlighted by the peak widths of all SAs, which is significantly lower compared to those obtained with the $5 \mu \mathrm{m}$ column. As already mentioned in previous work, the best performances of the core-shell column can be explained taking in account that this technology is made with particles with more regular narrow size distribution. Considering the van Deemter equation $\left(\mathrm{H}=\mathrm{Ad}_{\mathrm{p}}+\mathrm{B} / \mu+\mathrm{C} \mu\right.$ where $\mathrm{H}=$ height equivalent to a theoretical plate, $d_{p}=$ particle diameter, $\mu=$ linear velocity),

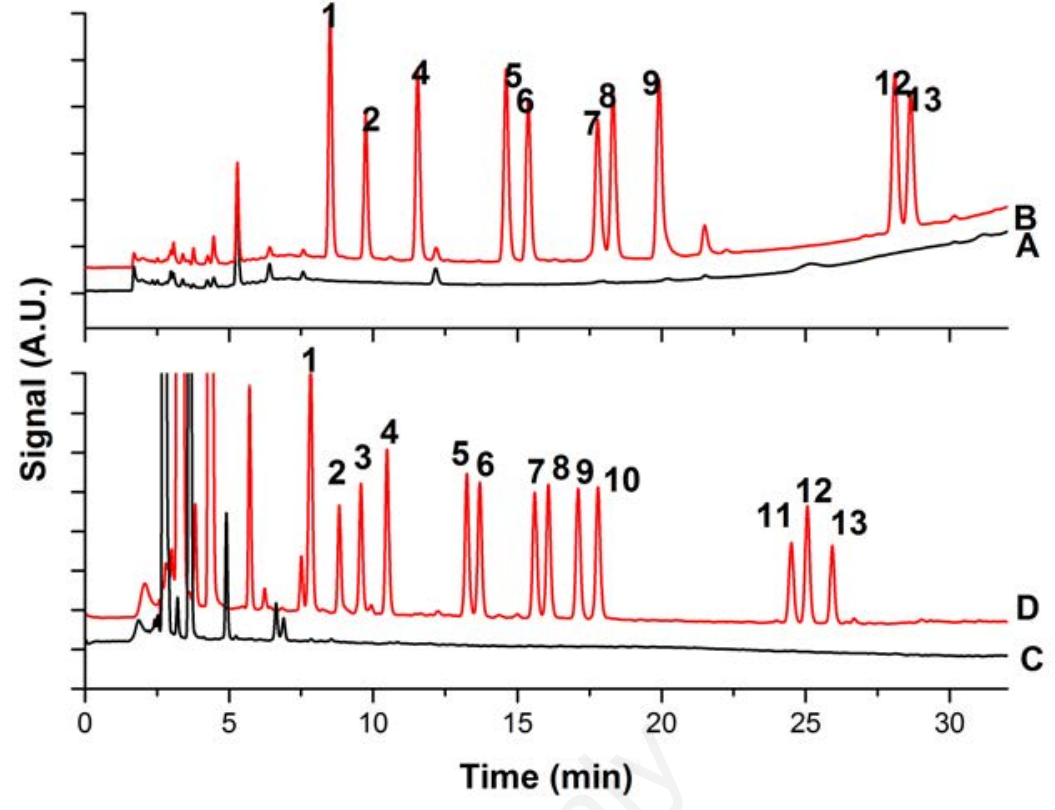

Figure 1. The chromatograms of (A) blank and (B) spiked feed samples at $10 \mathrm{mg} / \mathrm{kg} \mathrm{of}$ sulphonamides and the chromatograms of (C) blank and (D) spiked meat samples at 100 $\mu \mathrm{g} / \mathrm{kg}$ of sulphonamides using a C18 LUNA column $(250 \times 4.6 \mathrm{~mm}$ i.d., particle size 5 $\mu \mathrm{m})$. Flow rate of $1.0 \mathrm{~mL} / \mathrm{min}$. Volume injection $20 \mu \mathrm{L}$. Elution gradient a (Table 1) was used to record chromatograms of $A$ and $B$. Elution gradient $b$ (Table 1 ) was used to record chromatograms of $C$ and D. 1) sulfadiazine; 2) sulfathiazole; 3) sulfapyridine; 4) sulfamerazine; 5) sulfamethazine; 6) sulfamethoxipyridazine; 7) sulfachloropyridazine; 8) sulfamonomethoxine; 9) sulfamethoxazole; 10) sulfadoxine; 11) sulfaphenazole; 12) sulfadimethoxine; and 13) sulfaquinoxaline.

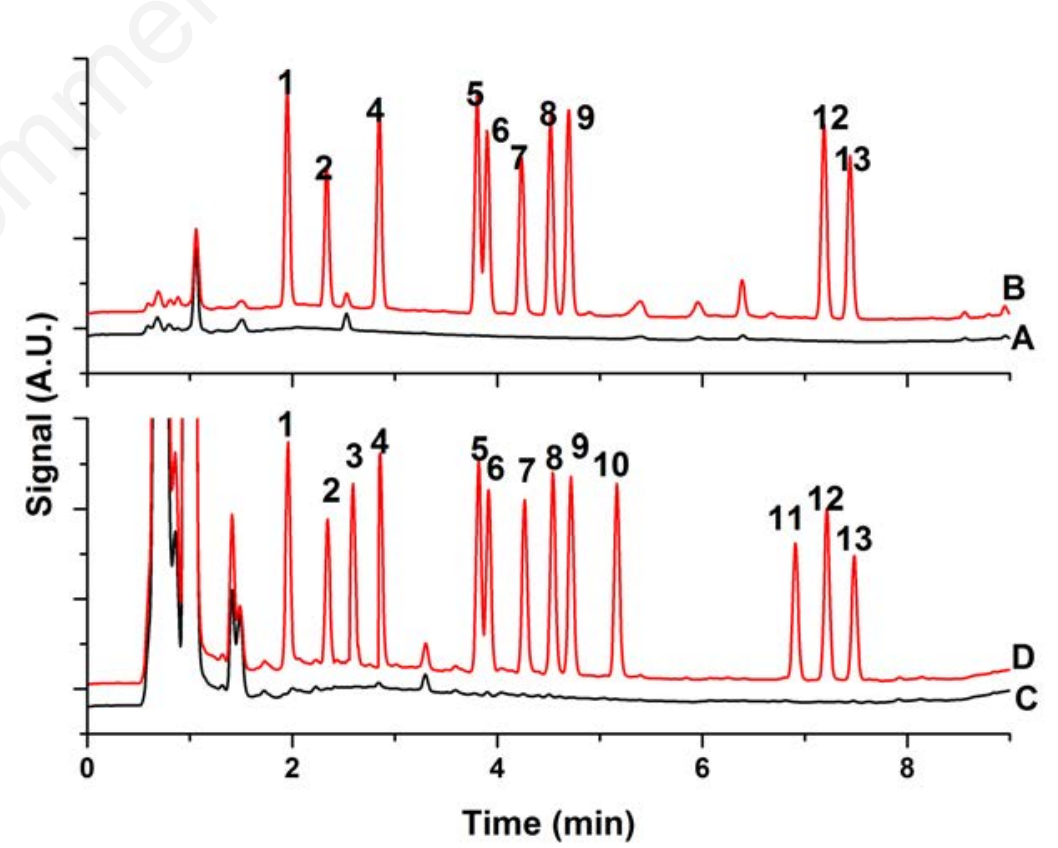

Figure 2. The chromatograms of (A) blank and (B) spiked feed samples at $10 \mathrm{mg} / \mathrm{kg}$ and the chromatograms of (C) blank and (D) spiked meat samples at $100 \mu \mathrm{g} / \mathrm{kg}$ using a Kinetex core-shell $\mathrm{C} 18$ column $(75 \times 4.6 \mathrm{~mm}$ i.d., particle size $2.6 \mu \mathrm{m})$. Flow rate of 1.2 $\mathrm{mL} / \mathrm{min}$. Volume injection $6 \mu \mathrm{L}$. Elution gradient c (Table 1) was used to record all chromatograms. 1) sulfadiazine; 2) sulfathiazole; 3) sulfapyridine; 4) sulfamerazine; 5) sulfamethazine; 6) sulfamethoxipyridazine; 7) sulfachloropyridazine; 8) sulfamonomethoxine; 9) sulfamethoxazole; 10) sulfadoxine; 11) sulfaphenazole; 12) sulfadimethoxine; and 13) sulfaquinoxaline. 
this particular design assures a strong reduction of two principal reasons of chromatographic peak dispersion: the eddy diffusion (term A in van Deemter equation) and reduction of mass transfer resistance (term $\mathrm{C}$ in van Deemter equation) (Gritti et al., 2007; Guichon and Gritti, 2011; Cabooter et al., 2010). The significant reduction of the mass resistant is due to the fact that core-shell particles are not fully porous.

Since no changes have been made on the extraction and clean-up steps, only few experiments are necessary to confirm that the values of the most important validation parameters of the two analytical methods are not affected by the change of the column.

\section{Conclusions}

In this work preliminary study on the applicability of a core-shell column for the analysis of SAs in matrices such as feed and meat have been shown. Our approach utilizes a conventional HPLC/DAD system and no updates in the experimental set-up are required. The optimized method allows the separation of 13 SAs with a fully elution gradient of 13 minutes. The proposed method permits a large saving of organic mobile phase with high efficiency, sensitivity and accuracy.

\section{References}

Borras S, Companyo R, Granados M, Guiteras $\mathrm{J}$, Perez-Vendrell AM, Brufau J, Medina M, Bosch J, 2011. Analysis of antimicrobial agents in animal feed. Trends Analyt Chem 30:1042-64.

Cabooter D, Fanigliulo A, Bellazzi G, 2010. Relationship between the particle size distribution of commercial fully porous and superficially porous high-performance liquid chromatography column packings and their chromatographic performance J Chromatogr A 1217:7074-81.

Dmitrienko SG, Kochuk EV, Apyari VV, Tolmacheva VV, Zolotov TA, 2014. Recent advances in sample preparation techniques and methods of sulfonamides detection. A review. Anal Chim Acta 850:6-25.

European Commission, 2002. Decision of December 2009 on pharmacologically active substances and their classifican regarding maximum residue limits in foodstuffs of animal origin, 657/2002/EC. In: Official Journal, L 15.

European Commission, 2004. Regulation of the European parliament and of the Council of 29 April 2004 on official controls performed to ensure the verification of compliance with feed and food law, animal health and animal welfare rules, 882/2004/EC. In: Official Journal, L 165.

Fekete S, Oláh E, Fekete J, 2012, Fast liquid chromatography: the domination of coreshell and very fine particles. J Chromatogr A 1228:57-71.
Gritti F, Cavazzini A, Marchetti N, Guiochon G, 2007. Comparison between the efficiencies of columns packed with fully and partially porous $\mathrm{C}_{18}$-bonded silica materials. J Chromatogr A 1157:289-303.

Gritti F, Guichoon G, 2012. Mass transfer kinetics, band broadening and column efficiency. J Chromatogr A 1221:2-40.

Guiochon G, Gritti F, 2011. Shell particles, trials, tribulations and triumphs. J Chromatogr A 1218:1915-38.

Hayes R, Ahmed A, Egge T, Zhang H, 2014. Core-shell particles: preparation, fundamentals and applications in high performance liquid chromatography. J Chromatogr A 1357:36-52.

Iammarino M, Palermo C, Nardiello D, Muscarella M, 2011. Optimization and validation of a confirmatory method for determination of ten sulfonamides in feeds by LC and UV-diode array detection. Chromatographia 73:75-82.

Kan CA, Meijer GAL, 2007. The risk of contamination of food with toxic substances present in animal feed. Anim Feed Sci Tech 133:84-108.

Lo Magro S, Armentano A, Campaniello M, Tancredi C, Muscarella M, 2012. Ottimizzazione e validazione di un metodo HPLC/DAD: determinazione simultanea di dodici sulfamidici nel muscolo. Laboratorio 2000 pp. 44-8.

Segato G, Benetti C, Angeletti R, Montesissa C, Biancotto G, 2011. Doxycycline and sulfadimethoxine transfer from cross-contaminated feed to chicken tissues. Food Addit Contam A 28:860-8. 